\title{
Commentary: The life in our years
}

\author{
Tomasz A. Timek, MD, PhD
}

From the Division of Cardiothoracic Surgery, Spectrum Health, Michigan State University College of Human Medicine, Grand Rapids, Mich

Disclosures: Author has nothing to disclose with regard to commercial support.

Received for publication Dec 12, 2018; accepted for publication Dec 12, 2018; available ahead of print Feb 6, 2019.

Address for reprints: Tomasz A. Timek, MD, PhD, Division of Cardiothoracic Surgery, Spectrum Health, Michigan State University College of Human Medicine, 100 Michigan Ave NE, Grand Rapids, MI 49503 (E-mail: tomasz.timek@spectrumhealth.org).

J Thorac Cardiovasc Surg 2019;158:980-1

0022-5223/\$36.00

Copyright (c) 2019 by The American Association for Thoracic Surgery

https://doi.org/10.1016/j.jtcvs.2018.12.031

Cardiac surgery in patients with advanced age is fraught with increased morbidity and mortality for almost all procedures, ${ }^{1}$ including isolated aortic valve replacement ${ }^{2}$ and coronary artery bypass grafting surgery. ${ }^{3}$ Proximal aorta and arch replacement surgery may pose particular risk to the elderly with novel endovascular therapies emerging for high- and prohibitive-risk patients. In this month's issue of the Journal, Preventza and colleagues ${ }^{4}$ from Baylor offer surgical benchmarking data for elective proximal aorta and arch replacement in a large cohort of 805 patients. The investigators found age to be an independent predictor of operative mortality and composite end point of mortality and persistent stroke or hemodialysis. These findings are not surprising, but the $16.3 \%$ mortality rate for octogenarians is sobering. A similar mortality rate of $13.5 \%$ was reported by Shah and colleagues ${ }^{5}$ in 37 octogenarians undergoing ascending aortic replacement but also included 13 patients with acute dissections. Lack of a difference in the rate of stroke in these complex elderly patients, a somewhat unexpected finding in the current study, was also observed by those investigators.

The study by Preventza and colleagues ${ }^{4}$ was undertaken to benchmark surgical results versus potential new endovascular therapies, yet this goal deserves further attention. Aortic arch debranching and endovascular stenting have been gaining clinical acceptance for high-risk patients requiring total arch replacement, but the present study included only 3 octogenarians who underwent total arch replacement, thus offering little risk-stratification guidance. The great preponderance of procedures in the 70to 79-year and the 80- to 89-year age groups were ascending aortic replacements with a hemiarch $(70.1 \%$ and $93.9 \%$ for the 2 groups, respectively), but currently few endovascular options for isolated ascending aneurysm are on the horizon because of the unique anatomic and hemodynamic milieu of the proximal aorta. " "Reverse" extra-anatomic arch debranching followed by transapical endovascular stenting has been reported recently for the treatment of an ascending aortic aneurysm, ${ }^{7}$ yet in its current form is reserved for prohibitive-risk patients only.

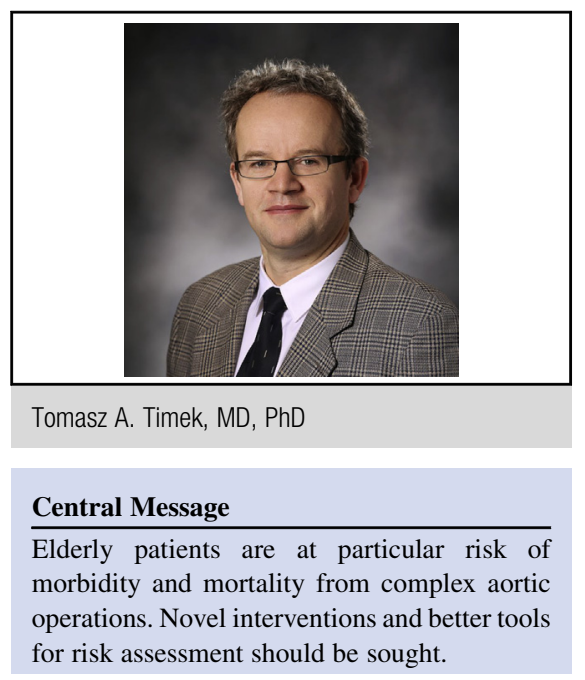

See Article page 973

Hospital disposition data presented by the authors deserve perhaps the greatest attention because $49.6 \%$ of patients aged more than 75 years were not discharged to home. These data corroborate the $36 \%$ facility discharge rate of 10,062 octogenarians undergoing valve surgery reported by Edmiston and colleagues. ${ }^{8}$ The ultimate fate of these patients is unknown, but return to prior level of function is questionable. Indeed, only $48.9 \%$ of patients with a mean age of 75.4 years discharged from the hospital to a facility were alive and living at home 1 year after cardiac surgery in a single-center study by Edgerton and colleagues. ${ }^{9}$ Frailty has recently been introduced into preoperative risk modeling predicting an increased likelihood of mortality, morbidity, and functional decline after open and transcatheter cardiac procedures. ${ }^{10}$ In proximal aortic surgery, the Duke group identified frailty as a predictor of discharge disposition and perioperative and 1-year mortality in a cohort of 148 frail patients with a mean age of only 63.4 years. ${ }^{11}$ In 288 patients undergoing aortic arch replacement with the elephant trunk technique, Estrera and colleagues ${ }^{12}$ demonstrated $8.7 \%$ mortality but with more than $50 \%$ of the 113 of 263 surviving patients not returning for the second-stage operation because of refusal for surgery or being deemed unfit. The mean age of the cohort was 62.4 years, with the upper quartile of the patients aged more than 73 years. These data underscore that aortic arch surgery presents a formidable challenge for patients beyond the usual 30-day morbidity and mortality even in younger patient cohorts. As frailty increases with 
age, aortic arch replacement in the elderly, even if performed with acceptable perioperative mortality, may significantly affect functional decline. Whether less-invasive endovascular therapies will offer better outcomes for these complex patients remains to be seen. No randomized trials of endovascular versus open aortic arch replacement have been undertaken, although single-center reports and meta-analyses do not suggest superiority of nontraditional interventions. ${ }^{13}$ Direct comparisons are difficult because sicker patients most often are treated with debranching and zone 0 endovascular therapy, but a small propensity-matched cohort described by Preventza and colleagues ${ }^{14}$ revealed a higher stroke rate with endovascular therapy with no difference in any other clinical outcomes, including length of intensive care unit or hospital stay.

Complex cardiac operations such as aortic arch replacement in the elderly behoove the surgeon to proceed with caution because surviving is not equivalent to living in a patient population who are often focused more on the life in their years than the years in their life. It is not a new procedure that we should perhaps be seeking, but more objective paths to predict the physiologic insult and debility the procedure is likely to inflict.

\section{References}

1. Alexander KP, Anstrom K, Muhlbaier LH, Grosswald RD, Smith PK, Jones $\mathrm{RH}$, et al. Outcomes of cardiac surgery in patients $>$ or $=80$ years: results from the national cardiovascular network. J Am Coll Cardiol. 2000; $35: 731-8$.
2. Agarwal S, Garg A, Parashar A, Svensson LG, Tuzcu EM, Navia JL, et al. In-hospital mortality and stroke after surgical aortic valve replacement: a nationwide perspective. J Thorac Cardiovasc Surg. 2015;150:571-8.

3. Natarajan A, Samadian S, Clark S. Coronary artery bypass surgery in elderly people. Postgrad Med J. 2007;83:154-8.

4. Preventza O, Price MD, Amarasekara HS, Ozozco-Sevilla V, Chatterjee S, Zhang Q, et al. In the endovascular era, is elective open aortic arch surgery in elderly patients still justified? J Thorac Cardiovasc Surg. 2019;158:973-9.

5. Shah PJ, Estrera AL, Miller CC, Lee TY, Irani AD, Meada R, et al. Analysis of ascending and transverse aortic arch repair in octogenarians. Ann Thorac Surg. 2008:86:774-9.

6. Kansal V, Hadziomerovic A, Nagpal S. Challenges of "reverse" aortic arch debranching for repair of the ascending aorta by thoracic endovascular aortic repair. EJVES Short Rep. 2016;32:29-32.

7. Canaud L, Albat B, Hireche K, Hostalrich A, Alric P, Gandet T, et al. Reverse extra-anatomic aortic arch debranching procedure allowing thoracic endovascular aortic repair of a chronic ascending aortic aneurysm. J Vasc Surg Cases Innov Tech. 2018;4:102-5.

8. Edmiston E, Dolansky MA, Zullo M, Forman DE. Octogenarians' post-acute care use after cardiac valve surgery and recovery: clinical implications. Geriatr Nurs. 2018;39:371-5.

9. Edgerton JR, Herbert MA, Mahoney C, Armstrong D, Dewey TM, Holper E, et al. Long-term fate of patients discharged to extended care facilities after cardiovascular surgery. Ann Thorac Surg. 2013;96:871-7.

10. Sepehri A, Beggs T, Hassan A, Rigatto C, Shaw-Daigle C, Tangri N, et al The impact of frailty on outcomes after cardiac surgery: as systematic review. J Thorac Cardiovasc Surg. 2014;148:3110-7.

11. Ganapathi AM, Englum BR, Hanna JM, Schechter MA, Gaca JG, Hurwitz LM et al. Frailty and risk in proximal aortic surgery. J Thorac Cardiovasc Surg. 2014; 147:186-91.

12. Estrera AL, Sandhu HK, Miller CC, Charlton-Ouw K, Nguyen TC, Afifi RO et al. Repair of extensive aortic aneurysms: a single-center experience using the elephant trunk technique over 20 years. Ann Surg. 2014;260:510-8.

13. Bachet J. Open repair techniques in the aortic arch are still superior. Ann Cardiothorac Surg. 2018;7:328-44. Review.

14. Preventza O, Garcia A, Cooley DA, Haywood-Watson RJ, Simpson K, Bakaeen FG, et al. Total aortic arch replacement: a comparative study of zone 0 hybrid arch exclusion versus traditional open repair. J Thorac Cardiovasc Surg. 2015;150:1591-8. 